\title{
Land Cover change detection by using Remote Sensing - A Case Study of Zlatibor (Serbia)
}

\author{
Dušan Jovanović $\mathrm{A}^{*}$, Miro GovedaricaA, Filip Sabo ${ }^{\mathrm{A}}$, Željko Bugarinović ${ }^{\mathrm{A}}$, \\ Olivera NovovićA, Teo Beker ${ }^{A}$, Miloš Lauter ${ }^{A}$ \\ Received: June 1, 2015 | Revised: July 29, 2015 | Accepted: October 30, 2015
}

\begin{abstract}
Change detection is a process of detecting differences with the objects or phenomena which are observed in the different time intervals. In this study different methods of analyzing satellite images are presented, with the aim to identify changes in land cover in a certain period of time $(1985-2013)$. The area observed in this study is the region of mountain Zlatibor (Serbia) with its surroundings. The methods represented in this study are vegetation indices differencing, Supervised classification and Object based classification. These methods gave different results in term of land cover area, and it is generally concluded that supervised classification gave the most accurate results with the images of medium spatial resolution. The results of this study can be used for urban and environmental planning. All information lead to conclusion that the surface under the forests is reduced for about $4 \%$ (or about $1000 \mathrm{ha}$ ) while the built up area has doubled (grown about $600 \mathrm{ha}$ ) during the examined period. The results also highlights the importance of change detection techniques in land cover for the areas that are developing rapidly, such as Zlatibor study area.
\end{abstract}

Key words: remote sensing, change detection, Landsat, supervised classification, OBIA

\section{Introduction}

Remote sensing is the science and to some extent, art of acquiring information about the Earth's surface without actually being in contact with it (Nanoh, et al., 2014). Remote sensing systems, in the first place those in the satellite platforms, provide continual and consistent view of the Earth making the ability of monitoring the earth's system and human influence on the Earth easier. The satellite development improves the possibility of collecting remote sensed data and it offers a good way for obtaining the information over the wide open areas. The capacity of the remote sensing to identify and monitor the earth's surface and the natural conditions has increased dramatically in the last few years and the remote sensing data are going to become, or they have already become, the crucial instrument in natural resource management. The remote sensor acquires a response which is based on many characteristics of the land surface, including natural or artificial cover (Anderson, et al., 1976). Remote sensing satellite imagery has given scientists a remarkable way to determine the reasons for land use/ land cover changes and the resultant consequences due to human activity (Cardille, Foley, 2003).

One of the most important benefits of the satellite for observing the earth is certainly the change classification and monitoring. In the last few years, numerous government agencies all around the world have used the satellite remote sensing to monitor and quantify the changes.

The Earth's surface is constantly changing in many ways. In the largest part of the world, the process of the soil changes is very dynamic. Apart from the seasonal rainfall and the possible interchangeable periods of the rainfall and drought, the man has influenced the vegetation changing the natural vegetation into the agricultural land, and vice versa where it was necessary. The other dynamic aspects are the natural

\footnotetext{
A Faculty of Technical Sciences, University of Novi Sad, Trg Dositeja Obradovića 6, 21000 Novi Sad, Serbia

* Corresponding author: Dušan Jovanović, e-mail: dusanbuk@uns.ac.rs
} 
disasters such us forest fires, floods, etc. which all influence changing of the Earth's surface. Since in the static environments, other methods of data collection, such as aerial images and land measuring, can give better thematic and spatial accuracy than the satellite remote sensing, the frequent flyover and shooting of the Earth with observational satellites allows the remote sensing to observe the dynamics of the area. The changes on the Earth's surface can be observed from the two aspects. Firstly, if time scale is observed when the changes have taken place, the changes can be different. In this sense the changes can be related to the variations of the natural disasters (e.g. floods, fires) or to the geological events (e.g. the creation of the continents), and in that sense time can be seen as a short period (fires that last for several hours or several days) or it can be one long continual period (the creation of the continents - several hundred years). Secondly, the changes can be observed from the spatial aspect, i.e. the occurance of the different changes as a consequence of a local event (a road or a bridge construction) or the changes on the global level (the increaseof the sea temperature or the melting of ice areas). When the changes on the Earth's surface are observed only from these two aspects, the time and spatial, it is clear that the nature of the change occurance is complex and it is very difficult to percieve and make a conclusion or make a decision, beacause of the mutual relation and dependance of these two factors. So, the change detection represents one very serious and challenging task. Determination of the changes which occure on the Earth in the context of the digital image processing require different procedures and techniques, some of which are standardised, while many other depend on the applications in which the image processing is being done. In order to compare one image to another it is necessary to compare the pixel of one image to the pixel of another. What is necessary to know before the detection proces itself is the value of the change phenomenon which is very important, i.e. it is necessary to conduct the filtration of the certain changes. This can vary from one user to another, and from the purpose of change detection.

There are several methods for mapping land cover changes using remotely sensed data, conventional maximum likelihood classification (Langford, Bell, 1997), post-classification, image differencing, and principal components change-detection techniques (Macleod, Congalton, 1998), image differencing, vegetative index differencing, post-classification change differencing, multi-date unsupervised classification (Mas, 1999).

The objective of this research is to assess, evaluate and monitor the nature and extent of land cover changes in Zlatibor area through the period from 1985 to 2013 using remotely sensed Landsat multispectral images. Four change detection techniques namely; vegetative index differencing, Supervised classification, combination of Magnitude Difference, Tasseled Cap and Color Difference algorithm and Object based classification were applied. The objective is to examine the effectiveness of each change detection technique and to classify the changed areas according to the "from-to" identifiers.

\section{Study area, data and methods}

Mountain Zlatibor and its surroundings have been chosen as a study area (Figure 1). Zlatibor is located between $43^{\circ} 31^{\prime} \mathrm{N}$ and $43^{\circ} 51^{\prime} \mathrm{N}$, and between $19^{\circ} 28^{\prime} \mathrm{E}$ and $19^{\circ} 56^{\prime} \mathrm{E}$. As a well-known holiday resort in all the seasons in the last 30 years Zlatibor is an area where planned and non-planned urbanization have left their

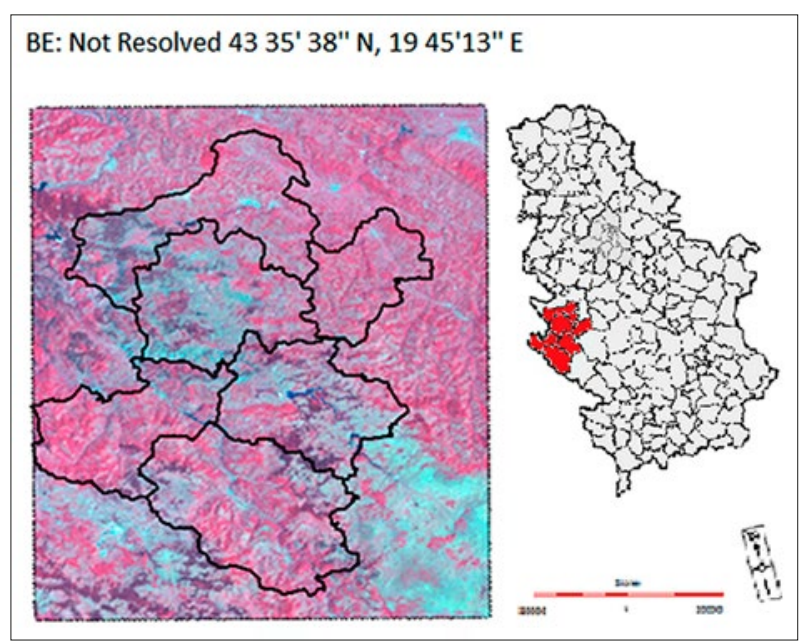

Figure 1. Landsat 5 TM image of Zlatibor study area in false color composite, R: 7 G: 5 B: 3

mark on the environment. Land use/land cover detection by using satellite images with medium spatial resolution is one of the ways which can offer the answers to what has happened in the observed area. Dominant land cover in observed area is coniferous and deciduous forest, although there is significant area of bare surfaces and urban area.

\section{Satellite images}

This case study used the images from Landsat 7 Enhanced Thematic Mapper + (ETM+) and Landsat 8 Operational Land Imager (OLI). The main differences between these sensors are in the numbers of the spectral ranges but also in the radiometric resolution, which is 16 bits for the Landsat 8 OLI platform, and 8-bits for the Landsat 7 ETM + (Table 1). The fact that different sensors with different spectral and radiometric resolution are used for change detection process 
Table 1. Landsat 7 (ETM+) and Landsat 8 (OLI and TIRS) platforms

\begin{tabular}{|c|c|c|c|}
\hline \multirow{8}{*}{$\begin{array}{l}\text { Landsat } 7 \\
\text { ETM+ } \\
\text { Bands } \\
(\mathrm{mm})\end{array}$} & Band 1 & $30 \mathrm{~m}$ Blue & $0.441-0.514$ \\
\hline & Band 2 & $30 \mathrm{~m}$ Green & $0.519-0.601$ \\
\hline & Band 3 & $30 \mathrm{~m}$ Red & $0.631-0.692$ \\
\hline & Band 4 & $30 \mathrm{~m} \mathrm{NIR}$ & $0.772-0.898$ \\
\hline & Band 5 & 30 m SWIR-1 & $1.547-1.749$ \\
\hline & Band 6 & 60 m TIR-1 & $10.31-12.36$ \\
\hline & Band 7 & 30 m SWIR-2 & $2.064-2.345$ \\
\hline & Band 8 & 15 m Pan & $0.515-0.896$ \\
\hline \multirow{11}{*}{$\begin{array}{l}\text { Landsat } 8 \\
\text { OLI and TIRS } \\
\text { Bands } \\
(\mathrm{mm})\end{array}$} & Band 1 & $30 \mathrm{~m}$ Coastal/Aeros & $0.435-0.451$ \\
\hline & Band 2 & $30 \mathrm{~m}$ Blue & $0.452-0.512$ \\
\hline & Band 3 & $30 \mathrm{~m}$ Green & $0.533-0.590$ \\
\hline & Band 4 & $30 \mathrm{~m}$ Red & $0.636-0.673$ \\
\hline & Band 5 & $30 \mathrm{~m} \mathrm{NIR}$ & $0.851-0.879$ \\
\hline & Band 6 & 30 m SWIR-1 & $1.566-1.651$ \\
\hline & Band 7 & 30 m SWIR-2 & $2.107-2.294$ \\
\hline & Band 8 & $15 \mathrm{~m}$ Pan & $0.503-0.676$ \\
\hline & Band 9 & $30 \mathrm{~m}$ Cirrus & $1.363-1.384$ \\
\hline & Band 10 & 100 m TIR-1 & $10.60-11.19$ \\
\hline & Band 11 & 100 m TIR-2 & $11.50-12.51$ \\
\hline
\end{tabular}

should be taken into account during the change detection.

Satellite images used in this study are from months of June and August from the following years: 1985, 2002, 2003, 2010, and 2013. During the summer there is no snow in the area of Zlatibor and rainfall is rare. Also during those months vegetation is in its optimum, which allows better image classification.

\section{Preprocessing}

Due to the inaccuracy of the sensing devices and smaller or bigger systematical mistakes, the preprocessing is an inevitable step in the change detection. In this study, the preprocessing included radiometric and geometric corrections of the satellite images. Radiometric correction comprised the process of histogram matching of the satellite images from different time periods, whereas geometric correction meant coregistration of the satellite images, so that the images could overlap in the best possible way. This is important because some of the essential methods are based on the comparison of the two images from different time periods, e.g. supervised classification.

\section{Methods of Land cover change detection}

Change detection has been defined as a "process of identifying differences in the state of an object or phenomenon by observing it in different times" (Singh, 1989). There are two basic ways of change detec- tion: first by direct overlapping of classified vector classes from both images and then visually analyzing the changes and second by direct change detection of one image made of combined images from different epochs (Jovanović, et al., 2007, Jovanović, et al., 2011). There is also a different classification given by Shaoqing. Methods of change detection can be classified into three categories: characteristic analysis of spectral type, vector analysis of spectral changes and time series analysis (Shaoqing, Lu, 2008). Characteristic analysis of spectral type is change detection based on spectral classification and calculations. The vector analysis is done by using strength and direction characteristics, and time series analysis is used to analyze process and trend of changes of monitored ground objects, based on continuously remotely sensed data. A serious problem for modeling urban landuse change has been the lack of spatially detailed data. GIS and remote sensing have the potential to support such models, by providing data and analytical tools for the study of urban environments (Manonmani, et al., 2010). The fundamentals of the used change detection methods are given below.

\section{Vegetation indices}

Vegetation indices are quantitative measurements indicating the vigor of vegetation (Campbell, 1987). They show better sensitivity than individual spectral bands for the detection of biomass (Asrar, et al., 1984). The interest of these indices lies in their usefulness in the interpretation of remote sensing images; they consti- 
tute notably a method for the detection of land use changes (multi temporal data), the evaluation of vegetative cover density, crop discrimination and crop yield prediction (Baret, 1986). In the area of thematic mapping, the interest of most of these indices lies in the improvement of classifications (Asrar, et al., 1984; Bariou, et al., 1985a, 1985b; Qi, et al., 1991; McNairn, Protz, 1993). In this study NDVI index was used in order to monitor vegetation cover changes during different time periods. Normalized Difference Vegetation Index (NDVI) is the most widely used vegetation index to distinguish healthy vegetation from others or from non-vegetated areas (Manandhar, et al., 2009). NDVI represents the ratio between the red (RED) and near infrared spectrum (NIR) (Equation 1) and was first used by Rouse et al. in 1973. Healthy plants absorb most of the visible light and reflect the large amount of the far-red and near-infrared light (Fluor Cam PAR, 2014.). It is obtained from the Equation 1. Theoretically, the values of this index will vary within the range of -1 to 1 . The research within this study showed that the values of NDVI index for vegetation are within the range between 0.3 and 0.7 , the values above 0.6 indicated the presence of dense vegetation.

$$
N D V I=\frac{\text { nir }- \text { red }}{\text { nir }+ \text { red }}
$$

Change detection with the use of the vegetation indices included the expert classification with the help of vegetation indices for the 25 -year period, between 1985 and 2010. The spectral signatures of the deciduous trees, coniferous trees, artificial objects and water areas have been extracted from the well-known regions and such spectral signatures were applied to the given Zlatibor area.

\section{DeltaCue}

One of the change detection methods used in this case study is completely automated. The software module Delta Cue from Erdas Imagine performs the automatic detection of the changes which happened between two images acquired in different time periods. The tool allows the determination of the spatial and spectral threshold of the changes which will be used, and the filtration of the changes in which the user is not interested. It is mainly used for: the detection of the important ecological changes, emergency situation management, identification of changes in the land use and land cover, assessment of the forest loss due to development or the diseases and identification of the new residential and infrastructure changes. The algorithms used for the change detection are: Magnitude Difference, Tasseled Cap and Color Difference algorithm. Magnitude Difference is a specific algorithm which calculates the sum of the squares of all the light values in all the ranges for each pixel of the image. The result of this algorithm contains all the information which was present in the initial shot, since the sum used the value intensities of all bands. Tasseled Cap algorithm converts the original image ranges (layers) in the new set of ranges (layers) with defined values which are useful for vegetation detection. Tasseled cap algorithm makes a linear combination of the original ranges, so every Tasseled Cap range consists of the sum of range 1 multiplied with the range constant, plus range 2 multiplied with the range constant, etc. The coefficients used for the creation of Tasseled Cap range are statistically derived from the images and empirical observations and they are specific for each sensor of the image.

\section{Supervised classification}

The third group of detection methods used in this study is based on the supervised classification. Change detection is based on the classification of all the image pixels from one time period in accordance with the pre-set number of classes, where the classes represent the appropriate land cover class. Change detection is the most common approach (post classification comparison) to detect the land use changes in terms of thematic classes (Al-Hassideh, et al., 2008, Foody, 2002). This is one of the methods which answers the question where and which changes have taken place. The two most basic types of classification methods are supervised and unsupervised classification. Both are machine learning methods. Unsupervised methods use specified number of classes and they mathematically recognize classes by measuring image pixels value differences. After that those once classified classes need to be classified and grouped again in the way that presents results as the operator wants. In supervised classification, it is necessary to select several characteristic training samples from the image for each of the classes. After that computer examines whole image and classifies pixels into one of the created classes. In this study, several different algorithms have been used for the classification of the surface cover: Parallelepiped classifier, classification based on the spatial characteristics, minimal distance and maximal conditional probability. Parallelepiped classifier was chosen to be used over all of the images. The characteristic of this classifier is that each element is compared to the bottom and top limit of the appropriate feature for the specific class. Usually those are the minimal, maximal or average values of the feature. Based on the supervised classification it can be indirectly detected where and which changes have taken place (Figure 2).

Maximum likelihood classification technique was performed using all spectral bands in each satellite image (Forkuo, et al., 2012, Langford, Bell, 1997). In 


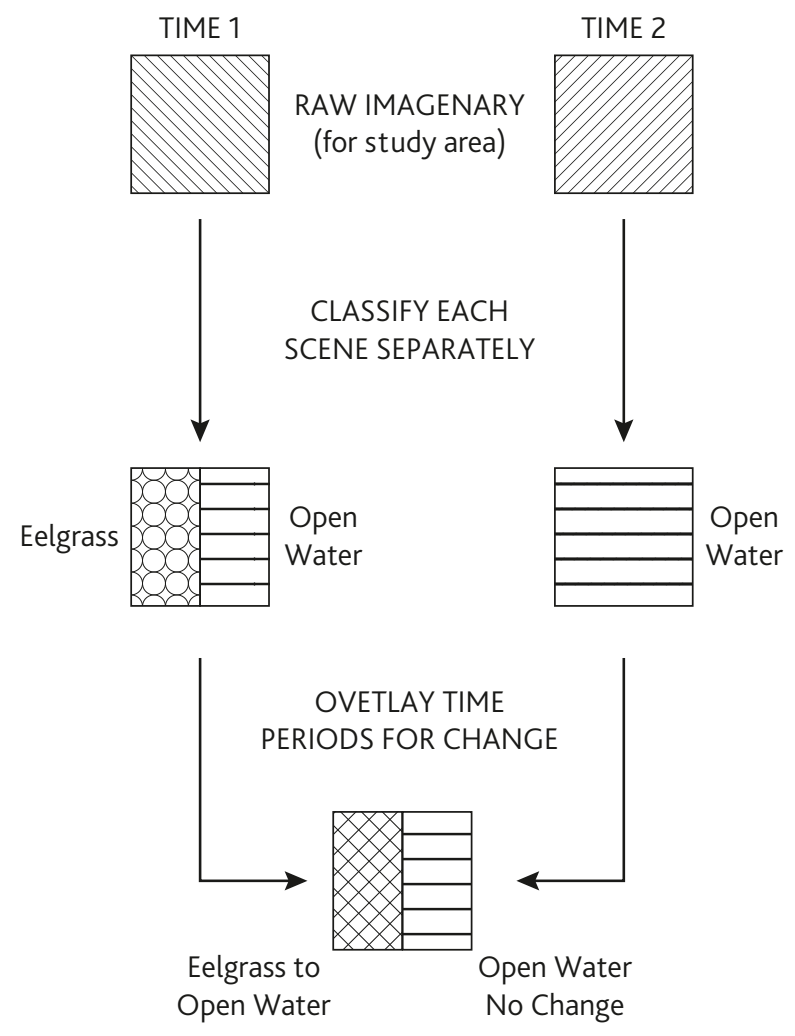

Figure 2. Post-classification change detection (Macleod, Congalton, 1998)

this study, the post-classification was used, which as a change detection method that represents an independent classification of the images from two time periods, and then the comparison of the results.

\section{Object based image analysis (OBIA)}

The last change detection method used in this study is based on the object based image analysis. OBIA represents a new way of classification, which was made due to the need to adjust the image processing process to the human understanding of an image, object and space. The classical classification methods view the image through the network of pixels and perform the processing based on the value of each pixel, i.e. grouping based on the spectral similarity. In the object based image classification, pixels are merged into objects, "grouping" is conducted in accordance with the complex criteria which include shape, texture, shade, size, mutual relations, and not only the value of a pixel. The first pre-condition for the automation of such way of extracting the object from an image is the existence of a procedure which will divide the picture into meaningful groups of data which could represent one object. This step is called the image segmentation. So, the segmentation is the basis of the object based classification, it represents the essence of the method, the other algorithms used in the processing procedure have the function of improving the result, elim- inating the segments which are below the minimal required probability, adjusting the segment shape to show the form of the object as realistically as possible, etc. Imagine Objective is a framework within ERDAS Imagine software which is used for the model creation and implementation of the object based classification procedure. To meet the needs of the Zlatibor area image analyses, the algorithm which includes the following functions have been tested: Raster Pixel Processor - SFP, Raster Object Creators - Segmentation, Raster Object Operators - Probability Filter, Size Filter, Dilate, Raster to Vector Conversion - Polygon Trace, Vector Object Operators - Generalize, Vector Object Processor - Geometry : Area and Vector Cleanup Operators - Dissolve, Smooth.

In the first step, the pixel classification is done based on the Multi Bayesian Network algorithm, which uses SFP (Single Feature Probability) to calculate the probability. SFP algorithm, based on the input image and the educational set allocates the value from o to 1 to each pixel, and based on that value it will be determined whether the pixel belongs to the object or the background. The next step in the analysis is the most important. There are several algorithms which are applied in this step, this study used the segmentation algorithm. In the segmentation algorithm, a raster is divided, based on the pixel value and position, in the smaller segments which represent wholes and which in the further analysis become candidates for an object. The probability threshold is set as a parameter, and based on it the further classification is done. The best results are obtained when the parameters are calculated automatically from the input data, there is an option for that in the algorithm parameter settings. The other steps represent the basic steps in reaching the final results.

\section{Results}

Although, there is not any ground truth data, some spectral signatures are obtained from regions where the land cover is well known. The analysis using NDVI index was carried out for several years: 1985, 2002 and 2003 with the goal to detect changes in vegetation cover. Figure 3 show the result of the expert classification applied to the index over the individual images. The class colors are the same for all the images, as follows:

- Green for deciduous forests

- Dark green for coniferous forests

- Blue for water areas

- Grey for unclassified

The following table (Table 2) gives the statistical data of vegetation index application. The data are also shown on the graphs: Figure 4. 


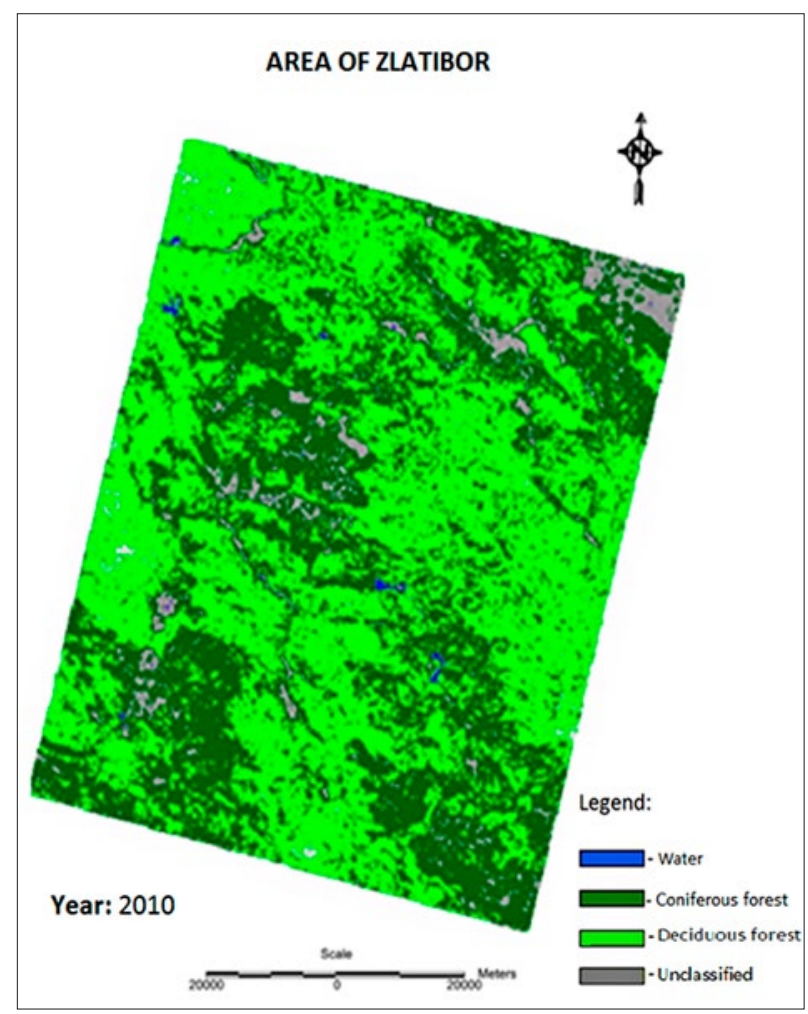

Figure 3. NDVI based classification, year 2010

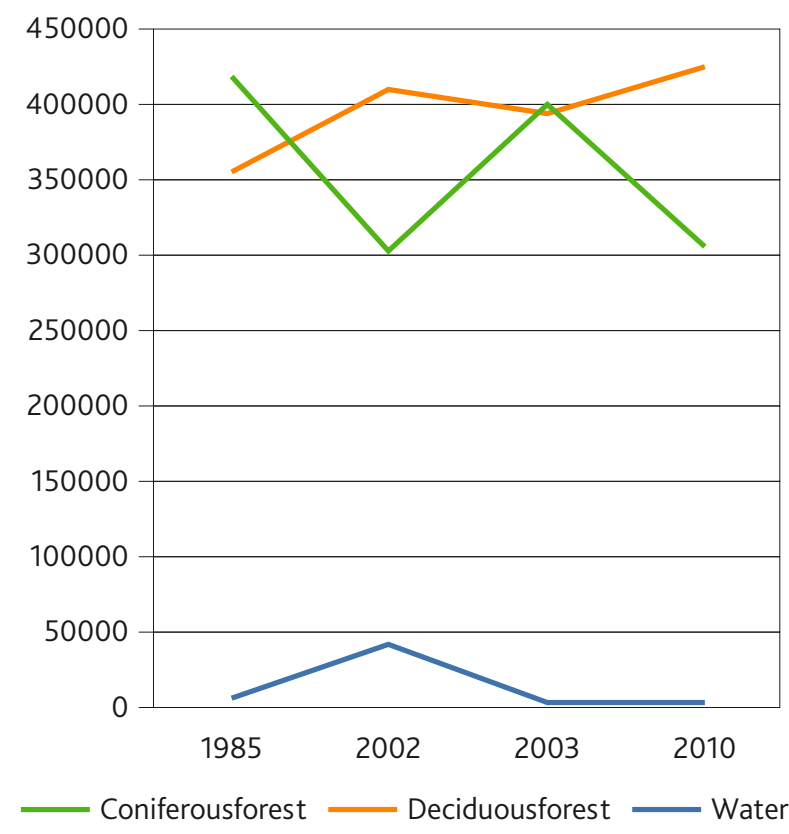

Figure 4. NDVI

Table 2. Vegetation index statistics [ha]

\begin{tabular}{|c|c|c|c|c|}
\hline Classes Year & $\begin{array}{c}1985 \\
\text { NDVI }\end{array}$ & $\begin{array}{l}2002 \\
\text { NDVI }\end{array}$ & $\begin{array}{l}2003 \\
\text { NDVI }\end{array}$ & $\begin{array}{l}2010 \\
\text { NDVI }\end{array}$ \\
\hline Coniferous forest & 417918 & 302303.88 & 397648.4 & 306756.27 \\
\hline Deciduous forest & 355149.2 & 407153.52 & 391776.7 & 423243.9 \\
\hline Water & 6284.43 & 41873.85 & 3521.52 & 4139.64 \\
\hline
\end{tabular}

IMAGINE DeltaCueaddition in ERDAS IMAGINE represented the second group of change detection methods in this study. Three types of algorithms have been used within the study:

- Magnitude Difference,

- Tasseled Cap,

- Color Difference Algorithm.

The results of these algorithms emphasise the important differencs between two images of the same area, which were made at the different time, but the result of these algorithms carries the information on the change from one class to another, where as the changes will not be shown for those classes which are the same on both images. The classes do not have names nor are marked based on the information they carry, but are given numerically so we need DeltaCue result interpretation to know which change has happened on the field (Figure 5).

In this study it was impossible to define the classes which appear as the result of the detected changes due to the lack of the historic data from the field which could assist this process. The results obtained in this way are important in terms of the spatial determination of the changes, but it is extreemely difficult to determine what each class represents (Figure 6), so this detection method changes was useless.

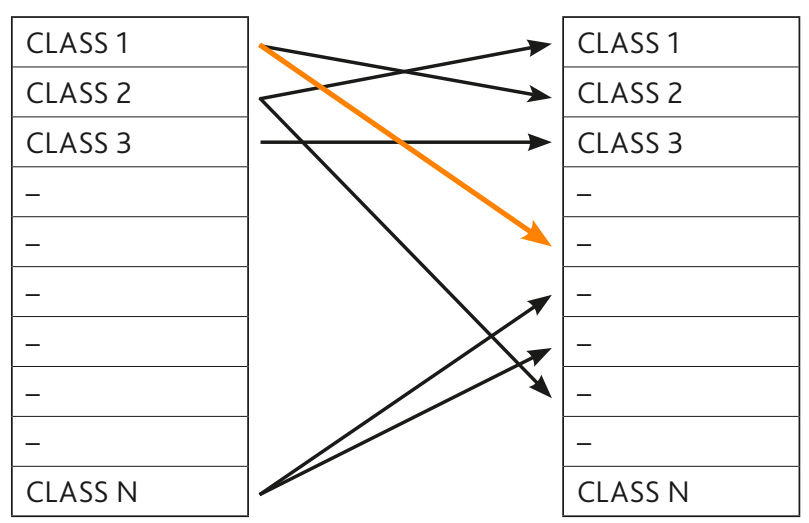

Figure 5. DeltaCue classes 


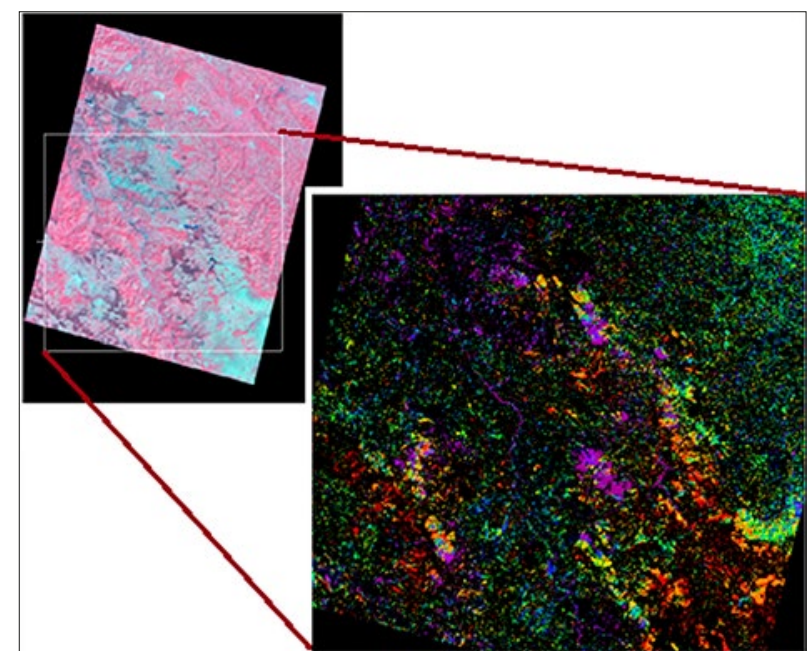

Figure 6. Detection of changes using DeltaCue in $1985-2013$ years

\section{Supervised Classification}

In the classification process, the selected images have been classified for the $6^{\text {th }}$ and $8^{\text {th }}$ month of a year. The images from 1985 and 2003 are from the $8^{\text {th }}$ month (august). Using the supervised approaches, six classes have been defined:

- water,

- vegetation (coniferous and other),

- artificial objects,

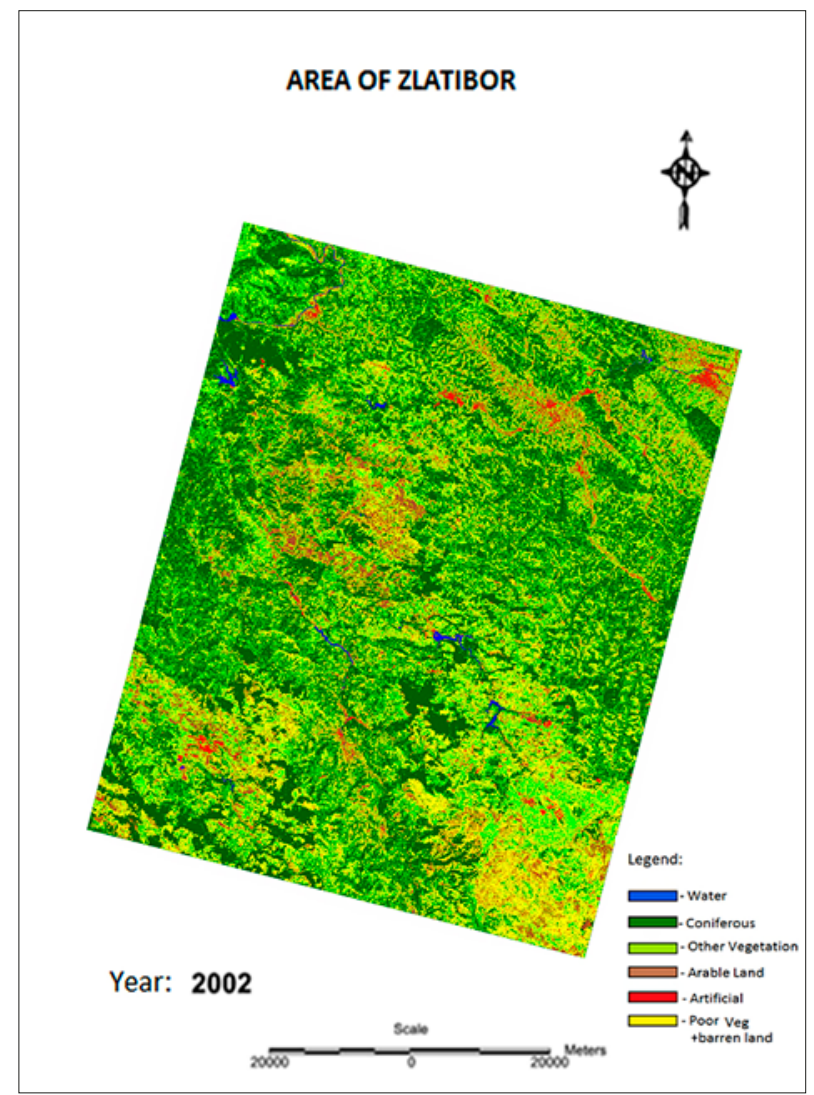

Figure 7. Supervised classification results for year 2002
- arable land,

- other (Sparse Veg. and barren land).

Vegetation is divided on the area covered with coniferous forest and other vegetation, which includes the grass areas too. The class 'other' is also very important, since it has a strong reflection which was often mixed with the artificial objects during the processing procedure. This class includes 'burnt' areas, mixed with the smaller rock stones, as well as the very sparse vegetation. The results of classification for all five years are given in the Table 3. The number of hectare that are classified in a given class for the corresponding year. Supervised classification was used for arable land, which defines the area under cultivation and a land under bad vegetation and barren land was classified as a special class. In Figures from 7 to 10 supervised classification results for four year is shown. From the graphs (Figure 11, Figure 12) it can be concluded that all the classes varied with smaller changes, and that the biggest discrepancies are in the year 2013. One of the reasons for the discrepancy can be found in the different platforms, since the image for 2013. is the only image from Landsat 8 platform. Landsat 8 has two infrared ranges, so the class labeled as 'the other vegetation' and the class "other" are differently classified in comparison with the Landsat 7 platform.

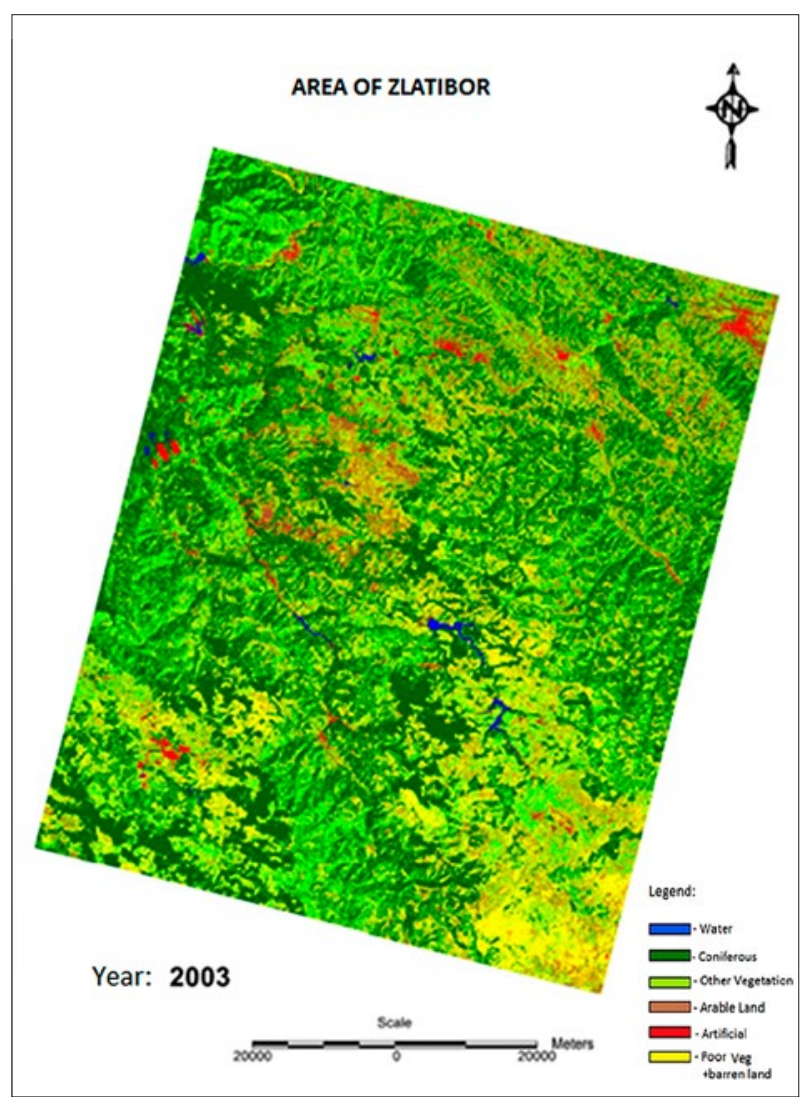

Figure 8. Supervised classification results for year 2003 


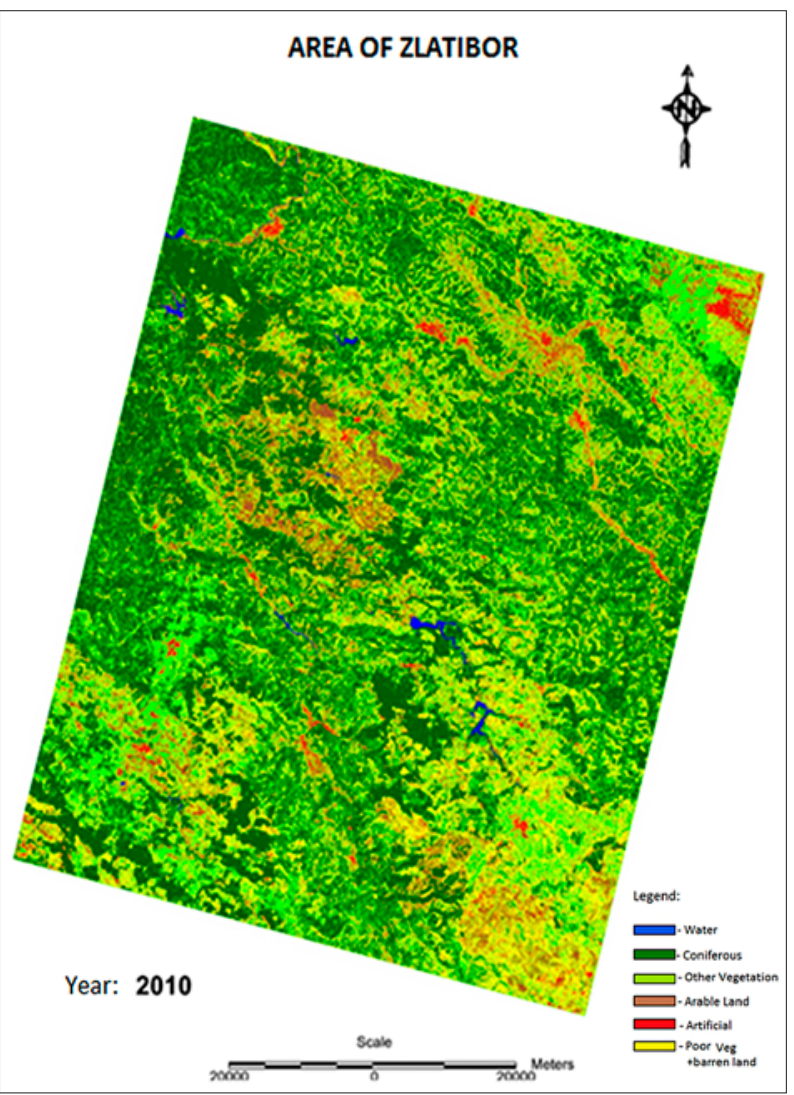

Figure 9. Supervised classification results for year 2010

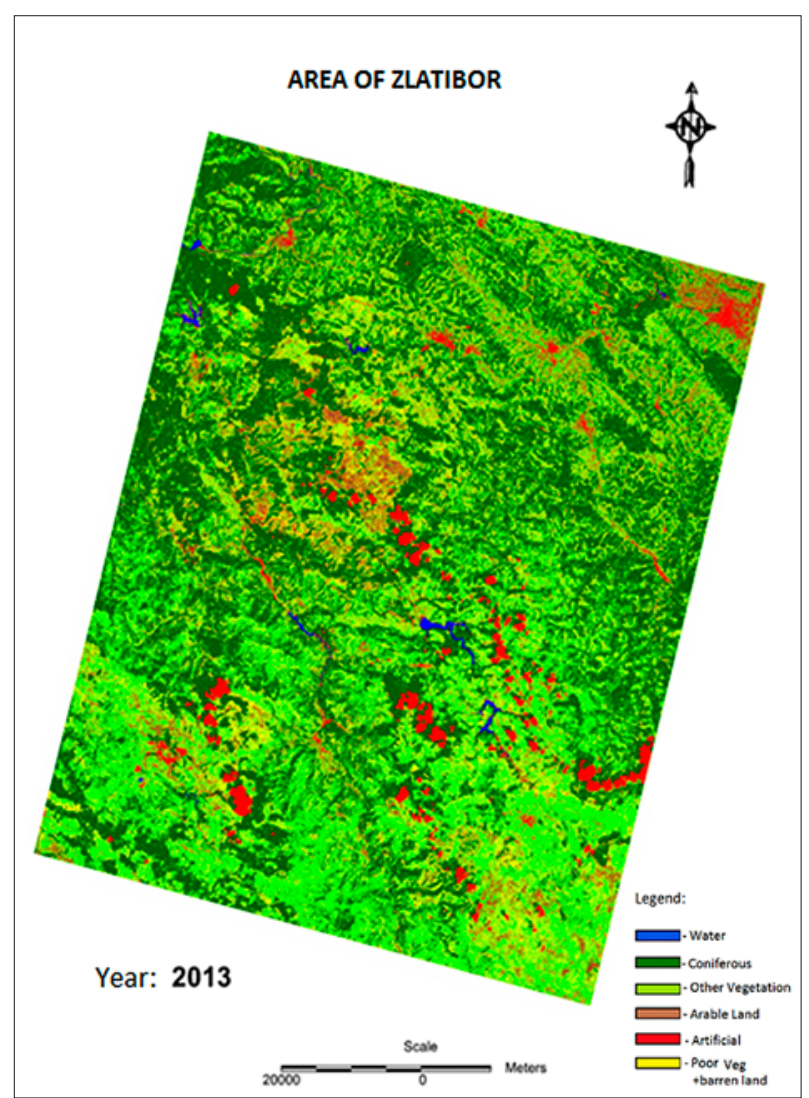

Figure 10. Supervised classification results for year 2013

Table 3. Classification results for all five time periods [ha]

\begin{tabular}{|l|c|c|c|c|c|}
\hline Classes & 1985 & 2002 & 2003 & 2010 & 2013 \\
\hline Water & 2099.7 & 2496.6 & 2282.04 & 2068.38 & 2177.28 \\
\hline Coniferous & 343687.5 & 345589.4 & 361992.2 & 358737.8 & 330619 \\
\hline Other Vegetation & 221711 & 212546 & 210452.6 & 209169.5 & 292263.9 \\
\hline Arable Land & 63856.17 & 60969.78 & 70103.43 & 56994.03 & 74312.64 \\
\hline Artificial & 6311.43 & 9856.8 & 6779.34 & 14015.97 & 19812.42 \\
\hline Sparse veg. and barren land & 188398.4 & 196003.6 & 175424.2 & 186380 & 105579.5 \\
\hline
\end{tabular}

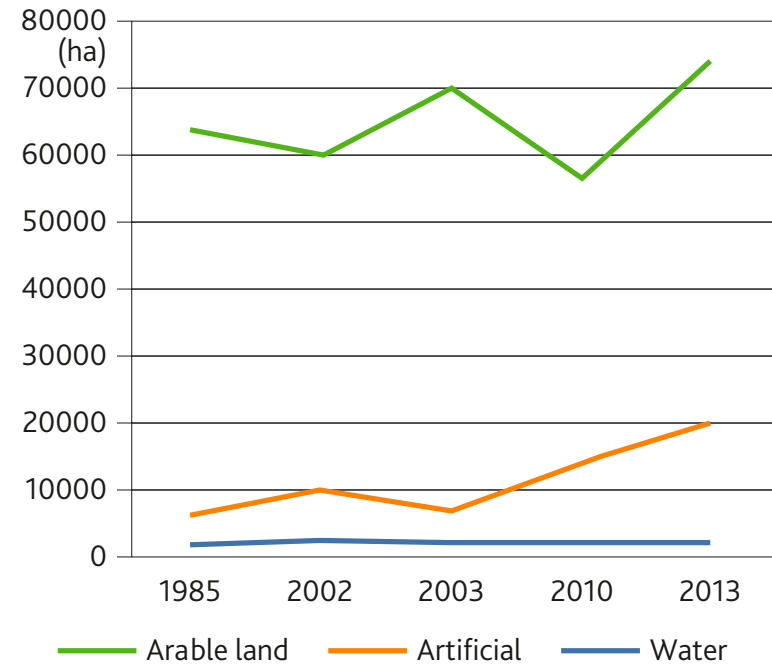

Figure 11. Results of supervised classification 1

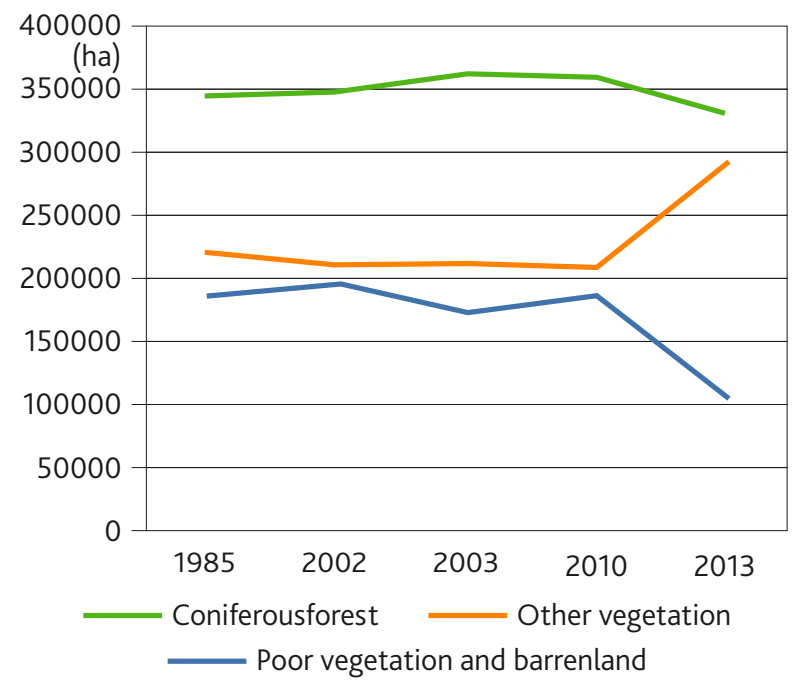

Figure 12. Results of supervised classification 2 
Table 4. Transition between the individual class of 1985 in 2003 (in the number of pixels)

\begin{tabular}{|c|c|c|c|c|c|}
\hline 1985 & 2003 & [pixels] & 1985 & 2003 & [pixels] \\
\hline \multirow[t]{6}{*}{ Water } & Coniferous & 2759 & \multirow[t]{6}{*}{ Other } & Coniferous & 389790 \\
\hline & Water & (18922) & & Water & 158 \\
\hline & Other Vegetation & 13 & & Other Vegetation & 530154 \\
\hline & Other & 5 & & Other & (891631) \\
\hline & Arable Land & 167 & & Arable Land & 268943 \\
\hline & Artificial & 1516 & & Artificial & 15522 \\
\hline \multirow[t]{6}{*}{ Other Vegetation } & Coniferous & 649117 & \multirow[t]{6}{*}{ Arable Land } & Coniferous & 52273 \\
\hline & Water & 350 & & Water & 80 \\
\hline & Other Vegetation & $(1102382)$ & & Other Vegetation & 191662 \\
\hline & Other & 498210 & & Other & 235383 \\
\hline & Arable Land & 207660 & & Arable Land & $(217915)$ \\
\hline & Artificial & 9266 & & Artificial & 13137 \\
\hline \multirow[t]{6}{*}{ Coniferous } & Coniferous & (2918801) & \multirow[t]{6}{*}{ Artificial } & Coniferous & 9375 \\
\hline & Water & 5262 & & Water & 584 \\
\hline & Other Vegetation & 506715 & & Other Vegetation & 7421 \\
\hline & Other & 314706 & & Other & 9206 \\
\hline & Arable Land & 65069 & & Arable Land & 19168 \\
\hline & Artificial & 13150 & & Artificial & (22735) \\
\hline
\end{tabular}

Table 4 shows the results of supervised classification of land cover change detection for period from 1985 to 2003 . Table 4 represents the transition of pixels from one to all other classes that are included in the analysis. The grey highlighted fields are the numbers of pixels which has remained in the same class (unchanged). It can be observed that the maximum overlaps are between classes: arable land, other vegetation

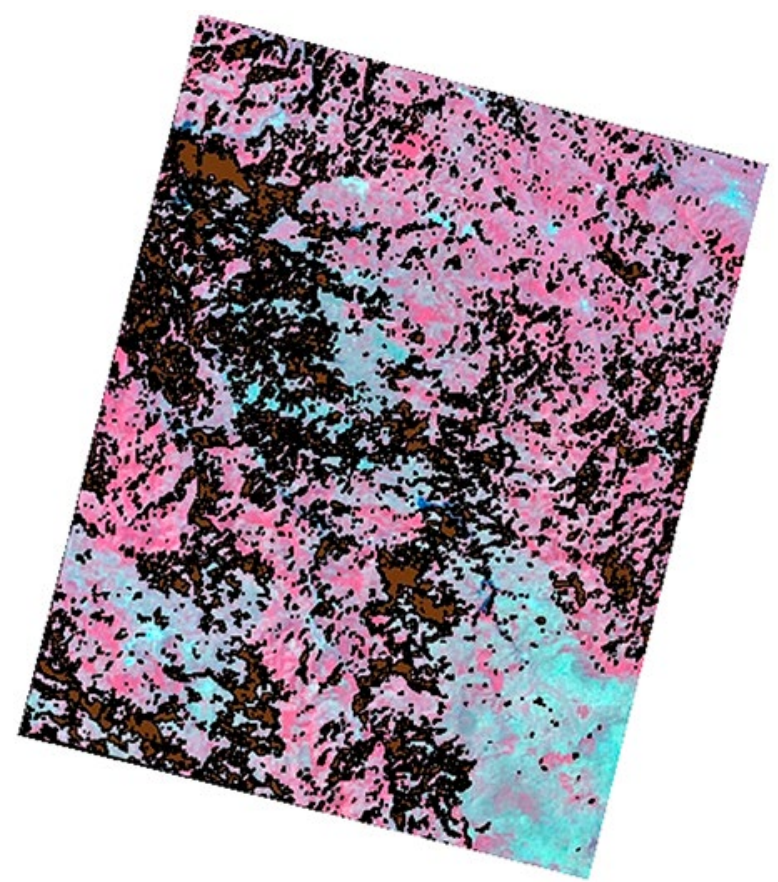

Figure 13. Original image and the resulted vector from object image classification, year 1985 and other classes. This was expected, because training sets for these classes are very similar. Accuracy of relevant class changes depends on spectral separability of classes involved (Mas, 1999).

In the end, the last change detection method used in this study is based on the object oriented image classification. The limitations which come with the spatial resolution of $30[\mathrm{~m}]$ have greatly influenced the

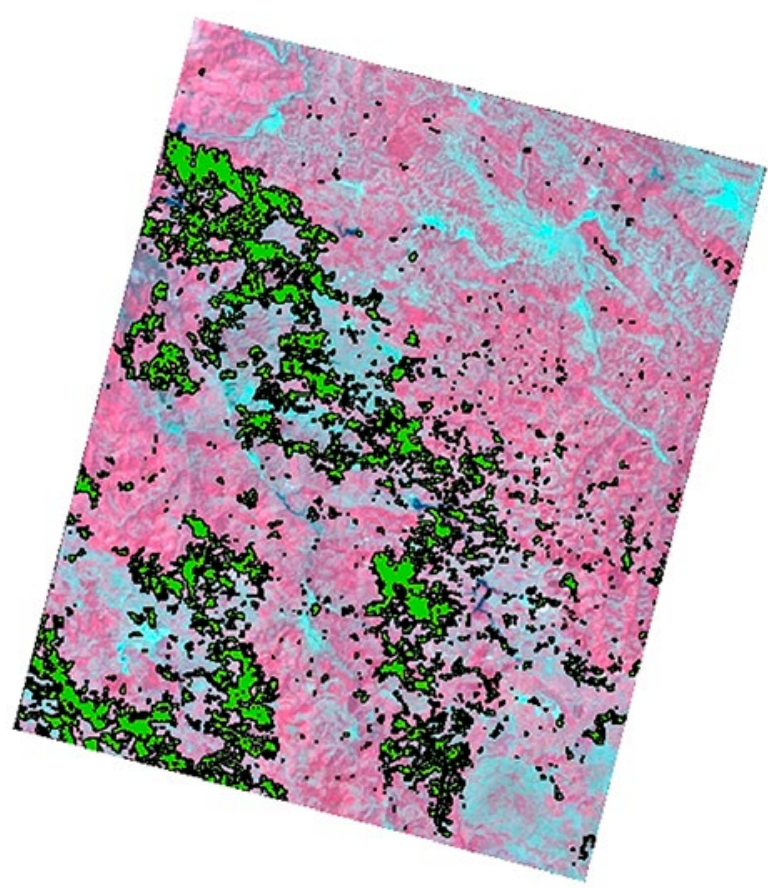

Figure 14. Original image and vector derived from object image classification, year 2002 
Table 5. Statistical results of the each method (shown in hectares)

\begin{tabular}{|c|c|c|c|c|c|c|}
\hline \multirow[t]{2}{*}{ Year: } & \multicolumn{6}{|l|}{1985} \\
\hline & Water & Coniferous & Other Veg. & Soil & Built-up & Other \\
\hline NDVI & 628.443 & 41791.797 & 35514.918 & & & \\
\hline Supervised & 209.97 & 34368.75 & 22171.104 & 6385.617 & 631.143 & 18839.84 \\
\hline Object vector & & 20251.872 & & & & \\
\hline Object raster & & 12046.329 & & & & \\
\hline \multirow[t]{2}{*}{ Year: } & \multicolumn{6}{|l|}{2002} \\
\hline & Water & Coniferous & Other Veg & Soil & Built-up & Other \\
\hline NDVI & 4187.385 & 30230.388 & 40715.352 & & & \\
\hline Supervised & 249.66 & 34558.938 & 21254.598 & 6096.978 & 985.68 & 19600.36 \\
\hline Object vector & & 19193.472 & & & & \\
\hline Object raster & & 14643.567 & & & & \\
\hline \multirow[t]{2}{*}{ Year: } & \multicolumn{6}{|l|}{2003} \\
\hline & Water & Coniferous & Other Veg & Soil & Built & Other \\
\hline NDVI & 352.152 & 39764.835 & 39177.666 & & & \\
\hline Supervised & 228.204 & 36199.215 & 21045.258 & 7010.343 & 677.934 & 17542.42 \\
\hline Object vector & & 22473.378 & & & & \\
\hline Object raster & & 17781.408 & & & & \\
\hline \multirow[t]{2}{*}{ Year: } & \multicolumn{6}{|l|}{2010} \\
\hline & Water & Coniferous & Other Veg & Soil & Built & Other \\
\hline NDVI & 413.964 & 30675.627 & 42324.39 & & & \\
\hline Supervised & 206.838 & 35873.784 & 20916.945 & 5699.403 & 1401.597 & 18638 \\
\hline Object vector & & 18330.03 & & & & \\
\hline Object raster & & 14764.203 & & & & \\
\hline \multirow[t]{2}{*}{ Year: } & \multicolumn{6}{|l|}{2013} \\
\hline & Water & Coniferous & Other Veg & Soil & Built & Other \\
\hline Supervised & 217.728 & 33061.896 & 29226.393 & 7431.264 & 1981.242 & 10557.95 \\
\hline
\end{tabular}

result of this method. What represents the continual object on the image of the $30[\mathrm{~m}]$ spatial resolution, on the image of the higher resolution can represent something completely different. Because of this there was a need to observe the objects through the spatial relations and the image semantics, and the need for precise defining of the object boundaries. Because of that, the classification has been done only for the evergreen area for the years 1985, 2002, 2003 and 2010. The obtained results were mutually compared for the years 1985 and 2002, and they were compared with the results obtained with the classical classification method. As it can be seen from the Figure 13, the results have encompassed the targeted are a pretty well.

The problems that occur during the processing and which can influence the result's accuracy to a certain extent are some smaller shaded areas which are recognized as an object and included in the classification. This problem can be minimized by the application of the appropriate operators, but it cannot be completely avoided due to the low spatial resolution of the image. The mitigating circumstance in this situation is the fact that the area under the evergreen forest is big, so the areas with the mistake can be ignored.

Figure 14 shows the original image and the vector obtained for 2002. It can be visually easily noticed that the area encompassed is smaller than for 1985 , certain mistakes have been removed with the work method, i.e. the application of the appropriate operators and the fixing of the training set itself.

\section{Conclusions}

Results of this research shown in Table 5 indicate that surface under coniferous forests and other vegetation has been reduced by $4 \%$ during the selected time frame. Also it shows the varying surface under water, which is as expected because of different rainfall and different water levels in the rivers. Built up area shows continuous growth, but in the year 2003 there is an error in supervised classification. Results also show that difference in the sensor used, between the years 2010 and 2013, in the classifications is noticeable. Some classifications gave too different results and be- 
cause of that are not shown, while more flexible method of supervised classification gave fine results.

This study showed several remote sensing change detection methods with Landsat images for the area of Zlatibor. The above mentioned methods gave the expected results in terms of the images with the spatial resolution of $30[\mathrm{~m}]$, which are a good representation of dense and homogenous areas with expected errors in parts of the image where areas change from one to another. Results of the comparison imply that supervised classification gave the results with the most classes making it the most comprehensive method used, while method like DeltaCue did not give any significant results.

In this study analysis of different approaches to change detection using medium spatial resolution imagery was done. Change detection between images, of Landsat 7 and 8 platforms, used in supervised classification analysis was difficult. The reason of this is the use of different platforms, and different sensors. The main difference of platforms Landsat 7 and 8 beside spectral resolution is radiometric resolution which is doubled on Landsat 8.

Supervised classification gave the results through all the stated classes and proved to be a more versatile method for the detection of a change. In the method vegetation indices is necessary to take into account the current humidity of the vegetation, so as to get the most objective results. The object based method only gave the results for the class of conifers, since that class was the observed object in this case. The object based method considered only class of conifers because this method can only work with large areas due to poor spatial resolution. With spatial resolution of $30[\mathrm{~m}]$ which was used in this study, the results of confirm the need for higher resolution if this method is supposed to be used. With low resolutions by using vectors results are only losing the accuracy. Other than that, ease of use and benefits of vectors make this method very desirable.

\section{References}

Al-Hassideh, Bill R. 2008. Land Cover Changes In The Region Of Rostock - Can Remote Sensing And Gis Help To Verify And Consolidate Official Census Data. Rostock University, Chair of Geodesy and Geoinformatics

Anderson, J. R., Hardy, E. E., Roach, J. T., Witmer, R. E. 1976. A Land Use and Land Cover Classification System for use with Remote Sensor Data. Geological Survey Professional Paper No. 964, U.S. Government Printing Office, Washington, D.C.

Asrar, G., Fuchs, M., Kanemasu, E. T., Hatfield, J. L. 1984. Estimating absorbed photosyntheticradia- tion and leaf area index from spectral reflectance in wheat. Agronomy Journal 76, 300-306

Baret, F. 1986. Contribution au suiviradiométrique de cultures de céréales. Thèse de Doctorat, Université Paris-SudOrsay, France, 182 pp. (in French)

Bariou, R., Lecamus, D., Henaff, F. 1985a. Indices de végétation. Dossiers de télédétection, Centre régional de télédétection. Université de Rennes 2, Rennes, France, 80 pp. (in French)

Bariou, R., Lecamus, D., Henaff, F. 1985b. Réponsespectrale des végétaux. Dossiers de télédétection, Centre régional de télédétection. Université de Rennes 2, Rennes, France, 71 pp. (in French)

Bello, M. N., Abbas, I. I., Akpu, B. 2014. Analysis of Land Use-Land Cover Changes in Zuru and Its Environment of Kebbi State, Nigeria Using Remote Sensing and Geographic Information System Technology. Journal of Geography and Earth Sciences 2, 1, 113-126

Cardille, Foley, J. A., 2003. Agricultural land-use change in Brazilian Amazonia between 1980 and 1995:evidence from integrated satellite and census data. Remote Sensing of Environment 87, 4, 551-562

Campbell, J. B. 1987. Introduction to Remote Sensing. The Guilford Press, New York, USA, 551 pp.

Canada Centre for Remote Sensing, 2015. Fundamentals of Remote Sensing.

Eric, F. K., Frimpong, A. 2012. Analysis of Forest Cover Change Detection. International Journal of Remote Sensing Applications 2, 4, 82-92

Foody, G. M. 2002. Status of land cover classification accuracy assessment. Remote Sensing of Environment 80, 1, 185-201

Fluor Cam PAR, 2014. Absorptivity Module \& NDVI Measurement Instruction Manual, product PSI, spol. s r. o., Drásov 470, 66424 Drásov, Czech Republic

Jovanović, D., Govedarica, M., Pržulj, Đ. 2007. Praćenje Promena Vodenih Površina Za Područje Vojvodine Korišćenjem Landsat ETM+ i TM Satelitskih Snimaka. Vodoprivreda 0350-0519, 39, 229-230, 337-343 (in Serbian with English summary)

Jovanović, D., Govedarica, M., Badnjarević, M. 2011. Presenting And Comparing The Object Based Image Analysis and Standard Image Analysis For Change Detection of Forest Areas, Using Low-Resolution Satellite Imagery. SGEM, 2, 11, 329-336

Langford M., Bell W. 1997. Land Cover Mapping in a Tropical Hillsides Environments: A Case Study in the Cauca Region of Columbia. International Journal of Remote Sensing 18, 6, 1289-1306

Macleod, R. D., Congalton, R. G. 1998. A Quantitative Comparison of Change Detection Algorithms for Monitoring Eelgrass from Remotely Sensed Data. Photogrammetric Engineering \& Remote Sensing 64, 3, 207-216. 
Manandhar, R., Odeh, I. O. A., Ancev, T. 2009. Improving the Accuracy of Land Use and Land Cover Classification of Landsat Data using Post-classification Enhancement. Remote Sensing 1, 3, 330-344.

Manonmani, R., Suganya, G. M. D. 2010. Remote Sensing and GIS Application In Change Detection Study In Urban Zone Using Multi Temporal Satellite. International Journal of Geomatics and Geosciences $1,1,60-65$

Mas, J. F. 1999. Monitoring Land-Cover Changes: A Comparison of Change Detection Techniques. International Journal of Remote Sensing 20, 1, 139-152

McNairn, H., Protz, R. 1993. Mapping corn residue cover on agricultural fields in Oxford County, Ontario, using Thematic Mapper. Canadian Journal of Remote Sensing 19, 2, 152-159

Rouse, J. W., Haas, R. H., Schell, J. A., Deering, D. W. 1973. Monitoring vegetation systems in the Great
Plains with ERTS. Third ERTS Symposium, NASA SP-351 I, 309-317.

Singh, A. 1989. Digital Change Detection Techniques Using Remotely Sensed Data, International Journal of Remote Sensing 10, 6, 989-1003

Shaoqing, Z., Lu, X. 2008. The Comparative Study Of Three Methods Of Remote Sensing Image Change Detection. School of Resource and Environment Science, Wuhan University, 129 Luoyu Road, Wuhan, China, 430079

Qi, J., Moran, M. S., Huete, A. R., Jackson, R. D., Chehbouni, A. 1991. View atmosphere soil effect on vegetation indices derived from SPOT images. Proceedings of the 5th International Symposium Physical Measurements and Signatures in Remote Sensing, Courchevel, France 2, 785-79o. 